\title{
Artificial Sweeteners: A Systematic Review and Primer for Gastroenterologists
}

\author{
Marisa Spencer, ${ }^{1}$ Amit Gupta, ${ }^{2}$ Lauren Van Dam, ${ }^{1}$ Carol Shannon, ${ }^{3}$ Stacy Menees, ${ }^{1}$ and William D Chey ${ }^{1 *}$ \\ Departments of ${ }^{1}$ Gastroenterology and ${ }^{2}$ Medicine, University of Michigan, Ann Arbor, Michigan, USA; and ${ }^{3}$ Taubman Health Sciences Library, \\ University of Michigan, Ann Arbor, Michigan, USA
}

Artificial sweeteners (AS) are ubiquitous in food and beverage products, yet little is known about their effects on the gastrointestinal (GI) tract, and whether they play a role in the development of GI symptoms, especially in patients with irritable bowel syndrome. Utilizing the PubMed and Embase databases, we conducted a search for articles on individual AS and each of these terms: fermentation, absorption, and GI tract. Standard protocols for a systematic review were followed. At the end of our search, we found a total of 617 eligible papers, 26 of which were included. Overall, there is limited medical literature available on this topic. The 2 main areas on which there is data to suggest that AS affect the Gl tract include motility and the gut microbiome, though human data is lacking, and most of the currently available data is derived from in vivo studies. The effect on motility is mainly indirect via increased incretin secretion, though the clinical relevance of this finding is unknown as the downstream effect on motility was not studied. The specific effects of AS on the microbiome have been conflicting and the available studies have been heterogeneous in terms of the population studied and both the AS and doses evaluated. Further research is needed to assess whether AS could be a potential cause of Gl symptoms. This is especially pertinent in patients with irritable bowel syndrome, a population in whom dietary interventions are routinely utilized as a management strategy.

(J Neurogastroenterol Motil 2016;22:168-180)

Key Words

Gastrointestinal tract; Irritable bowel syndrome; Microbiota; Motility; Sweetening agents

\section{Introduction}

Irritable bowel syndrome (IBS), a syndrome that is characterized by recurring episodes of abdominal pain, bloating, and altered bowel habits, is a common problem that is seen in approximately $10-20 \%$ of the general population. ${ }^{1,2}$ Roughly two thirds of patients with IBS associate the onset or worsening of their symptoms with food intake. ${ }^{3-6}$ To date, the greatest attention has focused on diets excluding FODMAPs (fermentable oligo-di-monosaccharides and polyols) or gluten in treatment of IBS symptoms. ${ }^{7,8}$ Many commercially available foods and beverages contain artificial sweeteners (AS), sometimes unbeknownst to the consumer. The prevalence of these nonnutritive sweeteners in products and their resultant ingestion by consumers has been increasing over time. ${ }^{9,10}$ The US Food and Drug Administration (FDA) has approved 5 AS to date: acesulfame, aspartame, neotame, saccharin, and sucralose. Other nonnutritive sweeteners, such as stevia, exist but these are not technically considered to fall under the term "artificial sweeteners." AS are often used for assistance with weight loss by decreasing the amount

Received: December 30, 2015 Revised: None Accepted: January 27, 2016

(c) This is an Open Access article distributed under the terms of the Creative Commons Attribution Non-Commercial License (http://creativecommons. org/licenses/by-nc/4.0) which permits unrestricted non-commercial use, distribution, and reproduction in any medium, provided the original work is properly cited.

*Correspondence: William D Chey, MD

1500 East Medical Center Drive, 3912 Taubman Center, PC 5362, Ann Arbor, Michigan 48109-5362, USA

Tel: +1-734-936-4775, Fax: +1-734-936-7392, E-mail: wchey@med.umich.edu 
of calories consumed from sugar. ${ }^{9}$ Some anecdotal evidence exists of AS triggering gastrointestinal (GI) symptoms in humans, but little has been published in the medical literature on this topic. The purpose of this review is to evaluate the available literature on the effects of AS on the GI tract in order to determine whether they could be playing a role in GI symptoms, especially those experienced by IBS patients.

\section{Methodology}

We first constructed a search strategy for PubMed which combined MeSH terms and free text terms to construct a broad discovery net for articles on individual AS and each of these terms: fermentation, absorption, and GI tract. The searches were then limited to full articles in the English language, and no other filters were applied. The search strategies were adapted to suit the Embase databases as well, and duplicate papers found in both databases were eliminated. All searches were completed by June 8, 2015. We retrieved potentially relevant articles and reviewed their reference lists to identify any studies missed by our search strategy. At the end of our search, we found a total of 617 eligible papers which were reviewed separately by 2 reviewers (MS and AG) and any discrepancies were resolved by a third party (SM); 591 papers were excluded because of irrelevance to the specific questions being asked, not written in English, case reports, letters to the editor, or reviews reporting data of the same original studies. In the end we selected 26 original papers to be included in our systematic review.

\section{Results}

Given the limited amount of data on the AS acesulfame and neotame, these AS were excluded from our review. Only data on aspartame (4 papers), saccharin (11 papers), and sucralose (14 papers) were included. Background data on the chemical structure (Figure), metabolism, and prevalence in commercially available products for each of the individual AS are presented first, followed by a summary of the evidence on their effects on motility, the microbiome, secretion, absorption/permeability, and GI symptoms. A sample of products that contain aspartame, sucralose, and saccharin are presented in Tables 1-3. Common food and beverage products and the AS they contain are presented in Table 4.

\section{Structure, Metabolism, and Prevalence}

Aspartame is a dipeptide methyl ester that is composed of the amino acids aspartic acid and phenylalanine (L-aspartyl-L-phenyl-<smiles>COC(=O)[C@H](Cc1ccccc1)NC(=O)[C@H](N)CC(=O)O</smiles>

Sucralose

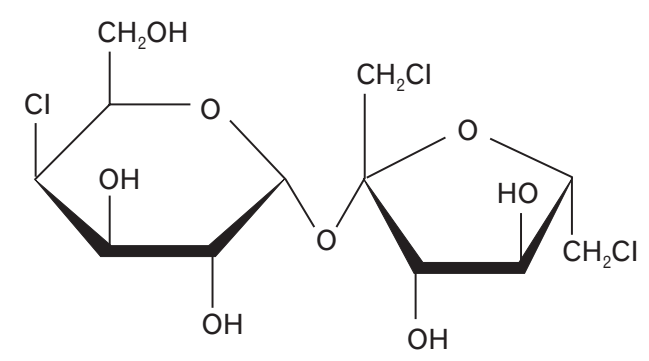

Saccharin

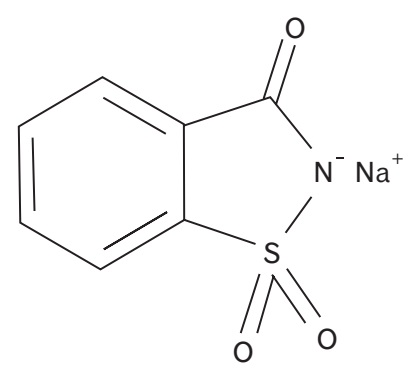

Figure. Chemical structures of artificial sweeteners.

alanine methyl ester). It is approximately 200 times sweeter than sucrose. ${ }^{11}$ Aspartame is hydrolyzed in the gut to its constituent amino acids, aspartate, and phenylalanine, as well as methanol which are all absorbed into the portal circulation. ${ }^{12,13}$ Methanol is then converted to formaldehyde and subsequently oxidized into formic acid. ${ }^{12}$ The amount of methanol from aspartame in a soft drink is less than that found naturally in many other foods/beverages. ${ }^{14,15}$ An ingredient search on foodfacts.com yields 2254 products that contain aspartame. The FDA's acceptable daily intake (ADI) of aspartame is 50 $\mathrm{mg} / \mathrm{kg} /$ day.

Sucralose $(\mathrm{C} 12 \mathrm{H} 19 \mathrm{Cl} 3 \mathrm{O} 8)$ is a synthesized disaccharide that is formed when 3 hydroxyl groups from sucrose are replaced with chlorine atoms. ${ }^{16}$ The resulting compound is around 600 times as sweet as sucrose. ${ }^{17}$ Splenda is a combination of sucralose and 
Table 1. Products Containing Aspartame

\begin{tabular}{ll}
\hline \multicolumn{1}{c}{ Products containing aspartame } & \multicolumn{1}{c}{ Additional non-nutritive sweeteners } \\
\hline Breath Savers Peppermint & Sorbitol \\
Crystal Light & Acesulfame K \\
Diet Coke & None \\
Diet Pepsi & Acesulfame K \\
JELL-O Sugar Free Gelatin Snacks & Acesulfame K \\
Mrs. Butterworth's Sugar Free Syrup & Acesulfame K, neotame, sorbitol \\
Orbitz Gum & Acesulfame K, sorbitol, xylitol, glycerol, mannitol \\
Snapple Diet Lemon Tea & None \\
Sprite Zero & Acesulfame K \\
Trident Gum & Acesulfame K, sucralose, sorbitol, xylitol, glycerin, mannitol \\
\hline
\end{tabular}

Table 2. Products Containing Sucralose

\begin{tabular}{ll}
\hline \multicolumn{1}{c}{ Products containing sucralose } & Additional non-nutritive sweeteners \\
\hline Altoids Smalls Sugar Free Peppermints & Sorbitol \\
Dasani Drops Flavor Enhancer & Acesulfame K \\
Diet V8 Splash & None \\
Fiber One Cereal - Original & None \\
Gatorade G2 Low Calorie & Acesulfame K \\
Glaceau FruitWater "naturally flavored sparkling water beverage" & None \\
Life Savers Sugar Free Hard Candy-Wild Cherry & Isomalt \\
Powerade Zero & Acesulfame K \\
Quaker High Fiber Instant Oatmeal Packets & None \\
Smucker's Sugar Free Strawberry Preserves & Polydextrose \\
Yoplait Light Yogurt & Acesulfame K \\
\hline
\end{tabular}

Table 3. Products Containing Saccharin

\begin{tabular}{ll}
\hline \multicolumn{1}{c}{ Products containing saccharin } & Additional non-nutritive sweeteners \\
\hline Diet Coke (Fountain soda at Burger King) & Aspartame \\
Diet Mountain Dew & Aspartame, acesulfame K \\
Fanta Zero Soda & Aspartame, acesulfame K \\
Fortuna Foods Pound Cake- Marble Flavor & None \\
Gold's Low Calorie Borscht (jar of beets) & None \\
Hainich Sweet Red Peppers & None \\
IBC Diet Root Beer & Aspartame \\
Schweppes Diet Tonic Water & None \\
Shasta Diet Grapefruit Soda & Aspartame \\
Tab Soda & Aspartame \\
\hline
\end{tabular}

maltodextran (1\% and $99 \%$ by dry-weight respectively). ${ }^{16}$ Given how potent sucralose is as a sweetener, these fillers are utilized to add volume. Radiolabeled sucralose studies have confirmed that approximately $85 \%$ of sucralose is eliminated unchanged in the feces. ${ }^{18,19}$ It should be noted that the absolute amount of sucralose eliminated in the feces is small given how potent it is as a sweetener.
The remaining approximately $15 \%$ of oral intake is absorbed following consumption. Most is excreted unchanged in the urine, but minor metabolites, likely the result of glucoronidation and not products of metabolism, have also been shown to be present in the urine. ${ }^{19}$ These metabolites represent only about $2-3 \%$ of the total oral intake. ${ }^{19}$ Both sucralose (unchanged) and the suspected gluc- 
Table 4. Common Products and the Artificial Sweeteners They Contain

\begin{tabular}{|c|c|}
\hline Products & Type of artificial sweetener/sugar substitute \\
\hline \multicolumn{2}{|l|}{ Beverages } \\
\hline $7 \mathrm{Up}$ Ten & Aspartame, acesulfame K (and HFCS) \\
\hline Coca-Cola Life & Stevia (and sugar) \\
\hline Country Time Lemonade On the go packets & Sucralose \\
\hline Crystal Light & Aspartame, acesulfame K \\
\hline Crystal Light Pure Fitness & Stevia (rebiana: Truvia brand) (and sugar) \\
\hline Dasani Drops Flavor Enhancer & Sucralose, acesulfame K \\
\hline Diet 7Up, Diet 7Up Cherry & Aspartame, acesulfame K \\
\hline Diet Canada Dry Gingerale & Aspartame, acesulfame $\mathrm{K}$ \\
\hline Diet Coke & Aspartame \\
\hline Diet Coke Cherry; Diet Coke Lime; Coke Zero & Aspartame, acesulfame $\mathrm{K}$ \\
\hline Diet Coke (Fountain soda at Burger King) & Aspartame, saccharin \\
\hline Diet Dr. Pepper; Diet Dr. Pepper Cherry & Aspartame \\
\hline Diet Mountain Dew & Aspartame, acesulfame $\mathrm{K}$, saccharin \\
\hline Diet Mug Root Beer & Aspartame \\
\hline Diet Pepsi, Diet Pepsi Wild Cherry & Aspartame, acesulfame K \\
\hline Dr. Pepper Ten & Aspartame, acesulfame K (and HFCS) \\
\hline Diet Sierra Mist & Aspartame, acesulfame $\mathrm{K}$ \\
\hline Diet Snapple (Diet Lemon Tea) & Aspartame \\
\hline Diet Snapple (Diet Half N' Half Tea) & Acesulfame K, sucralose \\
\hline Diet V8 Splash & Sucralose \\
\hline Fanta Zero soda & Saccharin, aspartame, acesulfame K \\
\hline Fresca & Aspartame, acesulfame K \\
\hline Gatorade G2 Low Calorie & Sucralose, acesulfame K \\
\hline Glaceau FruitWater "naturally flavored sparkling water beverage" & Sucralose \\
\hline Glaceau VitaminWater Zero & Erythritol, stevia \\
\hline Glaceau VitaminWater Zero Drops & Stevia \\
\hline Honest tea & Stevia (and sugar) \\
\hline Kool-aid powdered liquid drink mix; singles & Sucralose, acesulfame K \\
\hline Lipton Diet Citrus Green Tea \& Diet Mixed Berry Green Tea & Aspartame, acesulfame $\mathrm{K}$ \\
\hline Minute Maid Just 15 Calories Fruit Punch & Aspartame, acesulfame K (and HFCS) \\
\hline Minute Maid Light Lemonade & Aspartame, acesulfame K (and HFCS) \\
\hline Minute Maid Pure Squeezed Light OJ & Sucralose, acesulfame K \\
\hline Minute Maid Drops (lemonade flavor) & Sucralose, stevia \\
\hline MiO Liquid Water Enhancer drops- Original & Sucralose, acesulfame K \\
\hline Mountain Dew Kick Start Orange Citrus & Sucralose, acesulfame K (and HFCS) \\
\hline Nesquik No Sugar Added Chocolate Low Fat Milk & Sucralose, acesulfame K \\
\hline Ocean Spray Diet Cranberry & Sucralose, acesulfame K \\
\hline Pepsi Next & Sucralose, acesulfame K (and HFCS) \\
\hline Pepsi MAX & Aspartame, acesulfame K \\
\hline Powerade Zero & Sucralose, acesulfame K \\
\hline Propel - Berry & Sucralose, acesulfame K \\
\hline Propel Liquid Enhancer (drops)-grape, Propel Powder Packs - Lemon & Sucralose, acesulfame K \\
\hline Pure Leaf Iced Tea - Diet Lemon & Sucralose, acesulfame K \\
\hline Schweppe's Diet Tonic Water & Saccharin \\
\hline SoBe Lifewater & Stevia (and sugar) \\
\hline SoBe Lifewater 0 Calories & Erythritol, stevia \\
\hline Sparkling ICE Waters/Lemonades & Sucralose, mannitol \\
\hline Sprite Zero & Aspartame, acesulfame K \\
\hline
\end{tabular}


Table 4. Continued

\begin{tabular}{|c|c|}
\hline Products & Type of artificial sweetener/sugar substitute \\
\hline Starbucks DoubleShot Energy - Vanilla Light (in can) & Sucralose \\
\hline Starbucks Frapaccino Light- Mocha (glass bottle) & Sucralose, acesulfame K \\
\hline Starbucks Sugar Free Vanilla Beverage Syrup & Sucralose \\
\hline Sunny D Original & Sucralose, acesulfame K, neotame \\
\hline Tab Soda & Saccharin, aspartame \\
\hline Tropicana Trop50 OJ & Stevia \\
\hline \multicolumn{2}{|l|}{ Desserts/Candy } \\
\hline Brach's Sugar Free Hard Candy - Cinnamon & Sucralose, isomalt, maltitol \\
\hline Breyer's Ice Cream: No Sugar Added and CarbSmart & Sorbitol, polydextrose, sucralose, Acesulfame K, glycerin \\
\hline Edy's Slow Churned No Sugar Added Ice Cream & Maltitol, sucralose, sorbitol, glycerin, polydextrose \\
\hline Hershey's Lite Chocolate Syrup & Acesulfame K \\
\hline Hershey's Sugar Free Chocolate Syrup & Sucralose, acesulfame K, erythritol, glycerin \\
\hline Hershey's Sugar Free Chocolates & Maltitol, polyglucitol, polydextrose \\
\hline JELL-O Sugar Free/Low Calorie Gelatin Snacks and Sugar Free Jello box mixes & Aspartame, acesulfame K \\
\hline JELL-O Reduced Calorie Pudding Cups - Chocolate & Xylitol, sucralose, acesulfame K \\
\hline JELL-O Cook and Serve Sugar Free Calorie Pudding Dessert (box) & Aspartame, acesulfame K \\
\hline Jelly Belly Sugar Free Gummy Bears & Sucralose, maltitol \\
\hline Jolly Rancher Sugar Free Hard Candy & Acesulfame $\mathrm{K}$, isomalt, polyglucitol syrup \\
\hline Klondike Bar - Sugar Free & Acesulfame K, sucralose, aspartame, maltitol \\
\hline Klondike Bar - 100 Calorie & Acesulfame K, sucralose, maltitol \\
\hline Life Savers Sugar Free Hard Candy - Wild Cherry & Sucralose, isomalt \\
\hline Pilsbury Sugar Free Frosting - Chocolate Fudge & Sucralose, maltitol, sorbitol, isomalt, polydextrose \\
\hline Pilsbury Sugar Free Chocolate Brownie Mix & Maltitol, sucralose, acesulfame K \\
\hline Russell Stover Sugar Free Pecan Delights & Sucralose, maltitol \\
\hline Skinny Cow Ice Cream Sandwich & Sucralose, acesulfame K, sorbitol, isomalt, polydextrose \\
\hline Skinny Cow Ice Cream Bar - Chocolate & Sorbitol, polydextrose \\
\hline Skinny Cow Dreamy Clusters Chocolate Candy & Maltitol, polydextrose, glycerin, erythritol \\
\hline Tastykake Sugar Free Cream Filled Cupcakes & Maltitol, polydextrose, maltitol Syrup, sucralose \\
\hline Twizzlers Sugar Free Candy & Acesulfame K, maltitol, sorbitol, glycerin \\
\hline Weight Watcher's Ice Cream Cones (Vanilla Fudge Sundae) & Sucralose, lactitol \\
\hline Werther's Original Sugar Free Candy & Isomalt, acesulfame-K \\
\hline \multicolumn{2}{|l|}{ Mints/Gum } \\
\hline Altoids Smalls Sugar Free Peppermints & Sucralose, sorbitol \\
\hline Breath Savers Peppermint & Aspartame, sorbitol \\
\hline Doublemint Gum & $\begin{array}{l}\text { Acesulfame K, aspartame, sorbitol, xylitol, maltitol, } \\
\text { mannitol, glycerol }\end{array}$ \\
\hline Dentyne Ice Peppermint Sugar Free Gum & $\begin{array}{l}\text { Sorbitol, maltitol, mannitol, acesulfame potassium, } \\
\text { aspartame, glycerin, sucralose }\end{array}$ \\
\hline Eclipse Sugar Free Gum & Sorbitol, maltitol, glycerol, aspartame, acesulfame K \\
\hline Extra Sugar Free Gum & Sorbitol, mannitol, glycerol, aspartame, acesulfame K \\
\hline Five Sugar Free Gum - Cobalt Cooling Peppermint & Sorbitol, glycerol, mannitol, aspartame, acesulfame K \\
\hline Ice Breakers Frost Mints & $\begin{array}{l}\text { Acesulfame K, aspartame, neotame, sucralose, isomalt, } \\
\text { xylitol, glycerin, maltitol }\end{array}$ \\
\hline Lifesaver's Sugar Free Mints & Sorbitol, aspartame \\
\hline Mentos Sugar Free Peppermints & Sucralose, acesulfame K, isomalt, polydextrose, glycerol \\
\hline Orbit Gum & Acesulfame K, aspartame, sorbitol, xylitol, glycerol, mannitol \\
\hline Pur Gum - Wintergreen & Xylitol, glycerol \\
\hline Spry Green Tea Sugar Free Gum & Xylitol \\
\hline
\end{tabular}


Table 4. Continued

\begin{tabular}{|c|c|}
\hline Products & Type of artificial sweetener/sugar substitute \\
\hline Stride Sugar Free Peppermint Gum & $\begin{array}{l}\text { Sorbitol, glycerin, mannitol, xylitol, acesulfame potassium, } \\
\text { aspartame, sucralose }\end{array}$ \\
\hline Trident Gum & $\begin{array}{l}\text { Acesulfame K, aspartame, sucralose, sorbitol, xylitol, } \\
\text { glycerin, mannitol }\end{array}$ \\
\hline Wrigley's Big Red Chewing Gum & Glycerol, aspartame, acesulfame K \\
\hline Wrigley’s Bubble Tape Gum & Acesulfame K, aspartame, glycerol \\
\hline \multicolumn{2}{|l|}{ Yogurt } \\
\hline Activia Greek Light Non-Fat Yogurt - Blueberry & Sucralose, acesulfame K \\
\hline Chobani: Simply Chobani 100 Calories & Stevia (and monk fruit extract) \\
\hline $\begin{array}{l}\text { Dannon: Light and Fit Regular \& Greek; Light and } \\
\text { Fit Protein Shakes }\end{array}$ & Sucralose, acesulfame K \\
\hline Dannon Activia: Light; Greek Light & Sucralose, acesulfame K \\
\hline Kroger Carbmaster Yogurt & Sucralose, acesulfame K \\
\hline Yoplait: Light; Greek Light; Greek 100 Calories Whips & Sucralose, acesulfame K \\
\hline \multicolumn{2}{|l|}{ Cereal } \\
\hline Cinnamon Toast Crunch Reduced Sugar (75\% less) & Sucralose \\
\hline Fiber 1 Original Cereal & Sucralose \\
\hline Fiber 180 Calorie Cereal - Chocolate & Sucralose \\
\hline Quaker Oatmeal: Low Sugar Instant Oatmeal Packets; & Sucralose \\
\hline High Fiber Instant Oatmeal & \\
\hline \multicolumn{2}{|l|}{ Snack bars } \\
\hline Pure Protein Bars - Chocolate Peanut Butter & Sucralose, maltitol, glycerin \\
\hline Quaker Chewy Bars: 25\% Reduced Sugar & Sucralose, glycerin, polydextrose \\
\hline Quaker Chewy Bars: 90 Calorie Bars & Sorbitol, glycerin \\
\hline Special K Bars - Chocolate Pretzel, Protein Meal Bar & Sorbitol, glycerin \\
\hline \multicolumn{2}{|l|}{ Condiments } \\
\hline Coffee-Mate Creamer - Sugar Free Hazelnut (liquid and powder forms) & Acesulfame K, sucralose \\
\hline Heinz Reduced Sugar Ketchup & Sucralose \\
\hline $\begin{array}{l}\text { International Delight Coffee Creamer - Fat Free \& } \\
\text { Sugar Free Toasted Hazelnut }\end{array}$ & Acesulfame K, sucralose \\
\hline Mrs. Butterworth's Sugar Free Syrup & Aspartame, acesulfame $\mathrm{K}$, neotame, sorbitol \\
\hline Smucker's Sugar Free Strawberry Preserves & Sucralose, polydextrose \\
\hline Smucker's Sugar Free Blueberry Syrup & Sucralose, acesulfame K, sorbitol \\
\hline Starbucks Sugar Free Caramel Syrup & Sucralose \\
\hline \multicolumn{2}{|l|}{ Shakes/supplements } \\
\hline Atkins Shakes- Dark Chocolate Royal & Sucralose, acesulfame K \\
\hline Benefiber Fiber Drink Mix - On the Go (Strawberry Kiwi) & Aspartame, acesulfame $\mathrm{K}$ \\
\hline Citrucel Sugar Free Orange Fiber Powder & Aspartame \\
\hline Glucerna Shake & Acesulfame K, sucralose, glycerol \\
\hline Glucerna Nutrition Bar & Acesulfame K, sucralose, glycerol, lactitol, maltitol, sorbitol \\
\hline GNC brand Pro Performance $100 \%$ Whey Protein - Vanilla Cream & Sucralose, acesulfame K \\
\hline Isopure Low Carb Protein Powder & Sucralose \\
\hline Metamucil Smooth Texture Orange Sugar Free Fiber Powder & Aspartame \\
\hline Optimum Nutrition $100 \%$ Whey Gold Standard Protein Powder & Acesulfame K \\
\hline Quaker Breakfast Shake - Chocolate & Sucralose \\
\hline Special K Protein Breakfast Shake & Sucralose, acesulfame K \\
\hline \multicolumn{2}{|l|}{ Fruit Cups } \\
\hline $\begin{array}{l}\text { Del Monte Fruit Cups - No Sugar Added } \\
\text { (Pears, Mandarine Oranges, Mixed fruit) }\end{array}$ & Sorbitol, sucralose, acesulfame K \\
\hline
\end{tabular}


uronide conjugates are excreted in urine with no bio accumulation. An ingredient search on foodfacts.com yields 5166 products that contain sucralose. Its higher prevalence compared with other AS is due to its stability in heat, its stability over a range of $\mathrm{pH}$ conditions, and its solubility in ethanol, methanol, and water. ${ }^{17}$ The FDA's ADI of sucralose is $5 \mathrm{mg} / \mathrm{kg} / \mathrm{day}$.

Saccharin is a strong organic acid with the chemical formula C7H5NO3S. It is almost completely ionized at physiological pH. Saccharin is 200-700 times sweeter than sucrose. It has nearly complete absorption from the gut (about $3 \%$ is recovered in the feces in humans after normal and high doses) ${ }^{20}$ and is rapidly eliminated unchanged in the urine. Metabolism of this molecule has not been detected. It is often used with other sweeteners, as it stores well, but is unstable when heated. Therefore, its prevalence in commercial products is much less compared with other AS. An ingredient search on foodfacts.com yields 110 products that contain saccharin. The FDA's ADI of saccharin is $5 \mathrm{mg} / \mathrm{kg} / \mathrm{day}$.

\section{Effects on Gastrointestinal Motility}

Evidence that AS may cause alterations in GI motility is mostly indirect, via their effects on the secretion of incretin hormones and serotonin. Certain AS, sucralose being the most studied, have been shown to cause increases in the incretin hormones glucagon-likepeptide-1 (GLP-1), gastric inhibitory polypeptide (GIP), Peptide YY (PYY), and cholecystokinin (CCK). GLP-1 decreases motility in the antro-duodeno-jejunal region and inhibits the migrating motility complex in healthy subjects and IBS patients. ${ }^{21} \mathrm{CCK}$ delays gastric emptying, ${ }^{22,23}$ and GIP may also slow gastric emptying. ${ }^{24,25}$ PYY has been shown to cause delayed intestinal transit. ${ }^{26,27}$ Additionally, sucralose has been shown to increase serotonin, which initiates peristaltic and secretory activity. ${ }^{28}$

\section{Cellular/animal studies}

Five studies done in cell lines showed that sucralose increased GLP1, GIP, PYY, CCK, and serotonin release. ${ }^{29-33}$ Another study, however, showed no difference in CCK and GLP-1 levels in duodenal tissue between the sucralose and control groups. However, there was a significant increase in both hormone levels above controls when sucralose was combined with pea protein, suggesting that there may be a synergistic relationship between a macronutrient and sucralose to enhance incretin release. ${ }^{34}$ Contrary to studies done at the cellular level, sucralose, saccharin, and acesulfame did not increase GLP-1 or GIP in rats ${ }^{35}$ despite the fact that the concentrations of the sweeteners used in the study were 1000 fold in excess of the amount used in diet soda.

\section{Human studies}

A number of human studies have been performed to assess the effect of AS on incretin secretion and thus GI motility indirectly. In 2009 Ma et al ${ }^{36}$ performed a controlled cross over trial on 7 healthy subjects (mean age 24 years old, mean body mass index [BMI] 21.6) who were given intragastric infusions of the following radiolabelled substances: $50 \mathrm{~g}$ sucrose in water, $80 \mathrm{mg}$ sucralose in 500 $\mathrm{mL}$ normal saline (NS), $800 \mathrm{mg}$ sucralose in $500 \mathrm{~mL} \mathrm{NS}$, and 500 $\mathrm{mL}$ NS. They found that sucralose did not stimulate GLP-1 or GIP release, and did not slow gastric emptying as assessed by carbon dioxide breath samples.

In 2011 Ford and colleagues performed a randomized controlled single-blind cross over study of 8 healthy humans ( 7 female, aged 22-27 years old, BMI 18.8-23.9). ${ }^{37}$ The study participants swallowed either $50 \mathrm{~mL}$ of water, sucralose $(0.083 \%$ sucralose), or maltodextran plus sucralose (Splenda, $0.083 \%$ sucralose), followed by a modified sham feeding (swish and spit) of same solution. Blood samples were taken before and up to 2 hours after. They concluded that sucralose ingestion did not increase plasma GLP1 or PYY levels. Additionally, sham feeding did not elicit a cephalic phase response for GLP-1.

Another randomized double-blinded placebo controlled cross over study looking at aspartame, sucralose, and acesulfame was performed in 2011 in 12 healthy, nonsmoking volunteers ( 6 female, mean age 23.3 [19-29] with a mean BMI 23 [20.5-24.7]). ${ }^{38}$ Subjects received intragastric infusions of 6 substances: aspartame, acesulfame, sucralose, fructose, glucose, and water. These were separated by at least 3-5 days. They found that equisweet loads of AS did not affect secretion of GLP-1 PYY, or ghrelin.

Brown et $\mathrm{al}^{39}$ performed a randomized controlled cross over trial looking at sucralose and acesulfame. In this study, 22 healthy volunteers (mean age 18.5 [12-25], 45\% males mean BMI [25.6]) drank $240 \mathrm{~mL}$ of Diet Rite cola or unflavored carbonated water 10 minutes prior to a $75 \mathrm{~g}$ oral glucose load. GLP-1 was measured for 180 minutes after the glucose load. They found that GLP-1 levels were significantly higher with diet soda than carbonated water, suggesting that sucralose given with glucose can enhance GLP1 release, though sucralose in the absence of carbohydrate did not seem to stimulate GLP-1 secretion in prior human studies. Effects on gastric emptying were not assessed as part of this study.

\section{Effects on the Microbiome}

There is a significant amount of evidence from animal studies that AS affect the gut microbiome but data on how specifically the 
sweeteners affect the microbiome are conflicting, and to our knowledge only one study has reported human data.

\section{Animal studies}

Anderson and colleagues first performed a controlled trial of male rats who were fed a $7.5 \%$ sodium saccharin $(\mathrm{NaS})$ diet or a control diet with no saccharin for 10 days in $1980 .^{40} \mathrm{NaS}$ resulted in an increase in the total number of aerobic microbes but no change in the number of total anaerobes, resulting in a lower anaerobes/aerobes ratio in the saccharin group. Visual inspection of plates showed that there was deletion of a specific anaerobic microbe in the $\mathrm{NaS}$ group, but this organism was not identified. Fifty or $100 \mathrm{mg} \mathrm{NaS}$ also inhibited the urease activity of proteus vulgaris likely due to inhibition of microbial growth (reduced numbers of organisms were present in culture tubes after 72 hours).

This same group then performed a follow up study that was published in $1985 .^{41}$ Rats were fed a control diet, or a diet that contained $\mathrm{NaS}$ at $5 \%$ or $7.5 \%$. $\mathrm{NaS}$ ingestion caused an increase in the mass of cecal contents and a dose-dependent increase in the fecal content of soluble polysaccharide, which resulted in more carbohydrate available to the gut microflora. $\mathrm{NaS}$ also caused inhibition of the hydrolysis of starch by amylase, an increase in the cecal concentration of lactate, and a decreased cecal concentration of volatile fatty acids compared with controls. $\mathrm{NaS}$ groups also showed decreased propioate, butyrate, and valerate levels compared with controls, and it was hypothesized that these results were due to effects on the microbiome.

Also in 1985, Mallett et $\mathrm{al}^{42}$ fed male rats a diet supplemented with $50 \mathrm{~g} \mathrm{NaS}$ for 4 or 20 weeks, or a control diet with no saccharin. ${ }^{42}$ The animals were subsequently sacrificed and their cecal contents were examined and enzyme assays were performed. The concentration and number of bacteria were determined by microscopic count. $\mathrm{NaS}$ over 4 weeks had no effect on the total bacterial counts, but after 20 weeks the total bacterial count had significantly increased, although the concetration of bacteria was similar to controls. The mean ammonia concentration in cecal contents increased by $30-50 \%$ in the saccharin group and the activity of a number of bacterial enzymes significantly decreased. Direct incubation of saccharin with cecal contents decreased nitrate reductase, B glucuronidase, and endogenous ammonia production. In this study they did not attempt to identify specific bacterial species. They hypothesized that the decreased enzyme activity may be how saccharin exhibits its effects on the microbiome.

A study done by Naim et $\mathrm{al}^{43}$ in 1985 measured bacterial counts of small intestinal contents of male rats after being incubated in vitro with $2.5 \% \mathrm{NaS}$ for up to 20 hours. They showed decreased counts of Lactobacillus and Escherichia coli compared with controls, and in particular $\mathrm{NaS}$ inhibited the growth of 3 Lactobacillus strains and $3 \mathrm{E}$. coli strains after their isolation from intestinal contents and incubation in laboratory medium. This study suggested the inhibitory effect of $\mathrm{NaS}$ on bacterial growth in pooled small intestinal contents in vitro and in pure culture. However, it should be emphasized that this study was done with small intestinal and not colonic samples, which may account for the different results seen in other studies.

Lawrie et $\mathrm{al}^{44}$ looked at the effect of $\mathrm{NaS}$ on the metabolism of amino acids by bacteria in rats in a study published in 1985. Male rats were given $7.5 \% \mathrm{NaS}$ in their diet or a control diet for 40 days. Rats in the study group had a 3-4 fold increase in the daily urinary excretion of indican and p-cresol (which are microbial metabolites of tryptophan). Phenol (another metabolite of tryptophan) was almost completely suppressed in the study group. The authors felt that saccharin changes the metabolism of amino acids by gut flora, leading to the formation of products with possible carincogenic properties. They also hypothesized that saccharin inhibits intestinal protein digestion leading to increased metabolism by bacteria.

In a study done by Pfeffer et $\mathrm{al}^{45}$ rats were sacrificed and their anaerobically recovered cecal contents were incubated with glucose. The addition of $\mathrm{NaS}$ and acesulfame $\mathrm{K}$ with the glucose inhibited anaerobic acid production by cecal bacteria. The authors felt the nutritive relevance of this was probably small becauase such high concentrations of $\mathrm{NaS}$ and acesulfame $\mathrm{K}$ were needed to inhibit fermentation.

A randomized controlled trial was performed by Abou-Donia et $\mathrm{al}^{46}$ in 2008 , in which male rats were randomly assigned to 1 of 5 groups: control, or sucralose plus maltodextran in the following doses (mg/kg/day): 1.1, 3.3, 5.5, or 11. Fecal pH and bacterial analysis were conducted weekly, and after 12 weeks half of the rats from each group were sacrificed. Small intestinal tissue was used to evaluate the effects of sucralose and maltodextran on levels of P-glycoprotein (P-gp) and cytochrome P-450 (CYP450). The remainder of the animals underwent a 12 week recovery period after which further assessment of pH/bacteria/P-gp, CYP450 was performed. During the duration of the study, no diarrhea in any of the rats was observed. In terms of the effect on the microbiome, they found that the total number of anaerobes decreased significantly in all sucralose plus maltodextran groups. At the lowest dose, total anaerobes were reduced by approximately $50 \%$ compared with controls. Bifidobacterium, Lactobacillus, and Bacteroides were significantly reduced at the lowest dose as well. Aerobic bacteria decreased significantly 
in all sucralose plus maltodextran groups except at the lowest dose (decreased by $51-68 \%$ of controls). The enterobacteria count was not different from the control population in any group. In the recovery period, the total anaerobes remained significantly lower in all groups, as did bifidobacteria (other specific bacteria were not significantly different from the controls). The mean fecal $\mathrm{pH}$ significantly increased in all sucralose plus maltodextran groups at end of 12 weeks and stayed significantly elevated in all groups except the lowest sucralose plus maltodextran group after 12 weeks of recovery. Sucralose plus maltodextran enhanced the intestinal expression of P-gp up to 2.4-fold, and increased CYP3A4 and CYP2D1 intestinal expression (though these effects were not seen in the group that received the lowest dose of sucralose plus maltodextran). In summary, sucralose plus maltodextran significantly decreased beneficial intestinal bacteria (ie, Bifidobacterium, Lactobacillus, and Bacteriodes), but had no effect on enterobacteria. Sucralose plus maltodextran also resulted in elevated fecal $\mathrm{pH}$ and enhanced intestinal expression of P-gp and CYP450 enzymes. Several parameters continued to differ after 12 weeks of recovery, including a decrease in the total number of anaerobes and enhanced P-gp and CYP expression.

Suez et $\mathrm{al}^{47}$ assessed the effect of AS in a multi-faceted study. The sweeteners NaS, sucralose, or aspartame were added to drinking water of mice (control mice drank only water or water supplemented with either glucose or sucrose). Impaired glucose tolerance was significantly increased in mice by consumption of the sweeteners $\mathrm{NaS}$, sucralose, and aspartame after 11 weeks. Given that $\mathrm{NaS}$ produced the most profound effect, it was decided to study this AS alone going forward. Changes in glucose tolerance were suppressed with antibiotic treatment, suggesting a direct role of the microbiome. Fecal microbiota composition was then determined by sequencing the $16 \mathrm{~S}$ ribosomal ribonucleic acid ( $\mathrm{rRNA}$ ) gene. Mice drinking $\mathrm{NaS}$ had a distinct microbial composition that clustered separately from their pre-saccharin microbiome and all controls at week 11. Bacteria that increased in abundance in $\mathrm{NaS}$ mice included bacteroides and some clostridiales (with other clostridiales under-represented). Lactobacillus was under-represented. Shotgun metanomic gene sequencing was performed in order to study the functional consequences of $\mathrm{NaS}$ consumption, and similar to the $16 \mathrm{~S}$ rRNA analysis, $\mathrm{NaS}$ treatment induced the largest changes in microbial relative species abundance. Pathways overrepresented in $\mathrm{NaS}$ mice included an increase in glycan degradation pathways in which glycans are fermented to form a number of compounds including short chain fatty acids.

They then transferred intestinal microbiota from mice fed $\mathrm{NaS}$ or control mice into germ-free mice, and those given microbiota from $\mathrm{NaS}$ group became more glucose intolerant than controls. Similar effects were seen in germ free mice that received microbiota that had been grown in vitro in the presence of $\mathrm{NaS}$. They concluded that $\mathrm{NaS}$ directly alters the microbiome composition and metabolism. An in vitro stool culture with saccharin increased Bacteriodes and reduced Firmicutes. Additionally, germ-free recipients of cultured configuration had increased Bacteriodes and under-represetation of several Clostridiales. The fecal microbiota composition of germ-free mice who received stool from saccharin mice showed different microbial composition as well.

\section{Human studies}

In the aforementioned study, Suez et $\mathrm{al}^{47}$ went on to assess the effect of AS on the microbiome in humans. They performed an observational study of a cohort of 381 non-diabetic humans who reported regular $\mathrm{NaS}$ consumption (based on a food frequency questionnaire). This data showed a correlation between $\mathrm{NaS}$ consumption and increase in central obesity, fasting blood glucose, Hemoglobin A1c, glucose tolerance test, and alanine aminotransferase. Furthermore, a subgroup analysis comparing high $\mathrm{NaS}$ consumers to non- $\mathrm{NaS}$ consumers showed a significant increase in Hemoglobin A1c even after correcting for BMI. One hundred and seventy-two randomly selected individuals from this cohort showed intestinal microbial changes chractertized by increases in Enterobacteriaceae, Deltaproteobacteria, and Actinobacteria phylum.

This group also performed a smaller trial of 7 healthy volunteers (5 male, 2 female, aged 28-36 years old) who did not normally consume $\mathrm{NaS}$ and who were given saccharin for 1 week at a dose of $5 \mathrm{mg} / \mathrm{kg}$. The majority of these (4/7), termed "NaS responders," developed poorer glucose tolerance and had altered intestinal microbiota when compared with the "NaS non-responders." None of the $\mathrm{NaS}$ non-responders showed an improvement in glucose tolerance. The microbiome of the $\mathrm{NaS}$ responders showed compositional changes by $16 \mathrm{~S}$ rRNA analysis. Germ-free mice that were given stool samples from $\mathrm{NaS}$ responders developed glucose intolerance, while those who were given stool from the same patients pre-NaS or from non-responders did not. Mice given stool from $\mathrm{NaS}$ responders showed an increase in Bacteroides fragilis and Weissella (of the order Lactobacillales) and a decrease in Candidatus Arthromitus (of the order Clostridiales). It is unclear what determined individual human responses to $\mathrm{NaS}$ consumption. It is also unclear whether $\mathrm{NaS}$ selects against certain microbes by inhibiting their function allowing competitors to flourish, or if it directly stimulates other organisms or both. 


\section{Effects on Secretion}

There are only 2 studies that assess the effect of AS on secretion in the GI tract. In a study performed by Kidd et $\mathrm{al}^{48}$ rat $\mathrm{G}$ cells exposed to sucralose showed increased gastrin secretion, which in turn regulates proliferative activity in the GI tract and gastric acid secretion.

Bianchi et $\mathrm{al}^{11}$ performed a controlled trial of male pylorusligated rats who were given $250 \mathrm{mg} / \mathrm{kg}$ aspartame intragastrically. After 5 hours the rats were killed and the gastric juice volume and concentrations were determined. Aspartame resulted in no inhibiton or stimulation of gastric juice, and no change in concentration of gastric acid. In vitro testing was also performed, and found that aspartame did not affect the proteolytic activity of pepsin or the lipolytic activity of pancreatic lipase.

\section{Effects on Absorption/Permeability}

Similarly, there is minimal data in the literature on the effect of AS on absorption and intestinal permeability. Two studies by Kimmich et $\mathrm{al}^{49}$ looked specifically at saccharin. In the first study, they isolated intestinal epithelial cells from chicks and found that saccharin had little direct effect on the sodium $(\mathrm{Na})$ dependent sugar transport system from the lumen to the intracellular space. They did find that passive transportation of sugar through the basolateral membrane was inhibited by saccharin. The inhibition of net efflux by saccharin allowed the active system to establish higher concentration gradients of sugars. There also appeared to be a non-specific effect that compromised the driving forces ( $\mathrm{Na}$ gradient) of the sugar transport system, which would limit delivery of sugar to the epithelial cell and into circulation. In a follow up study, ${ }^{50}$ the same group hypothesized that the nonspecific effect of saccharin on $\mathrm{Na}$ coupled sugar transport could be caused by inducing a change in the permeability of the cell membrane to $\mathrm{Na}$, which would diminish the $\mathrm{Na}$ gradient and inhibit sugar transport. However, results actually showed the opposite, that saccharin inhibits Na permeability, so therefore it should not inhibit glucose transport into the cell.

\section{Effects on Gastrointestinal Tract/Gastrointestinal Symptoms}

There is minimal data (and no human data) on the effect of AS on GI symptoms, stool form, GI histology, and alterations in the anatomy of the GI tract. Anderson and Kirkland ${ }^{40}$ noted that the stool of rats fed a diet of $7.5 \% \mathrm{NaS}$ for 10 days was softer compared with controls (not the typical pellets that are seen), and was not as odiferous per laboratory technician report. Additionally, in the $\mathrm{NaS}$ group the cecal tissue weight increased by $45 \%$ and the weight of cecal contents increased by $80 \%$, which was hypothesized to be due to osmotic effect of $\mathrm{NaS}$. In a follow up study done by the same group, 49 male rats were fed a control diet or a diet with different concentrations of $\mathrm{NaS}\left(1 \%, 3 \%, 5 \%\right.$, or $7.5 \%$ of their chow) ${ }^{51}$ They found that stool water increased 4-fold in the group fed $\mathrm{NaS}$ at $7.5 \%$ compared to the control group, but the stool dry weight remained constant. $\mathrm{NaS}$ resulted in a dose-dependent increase in the stool content of an unidentified carbohydrate, and it was hypothesized that this may represent an undigested polysaccharide or polysaccharide synthesized by the microbiota. The cecal enlargement and increased water in the saccharin groups was thought to be secondary to high stool saccharin content and increased stool hydration.

Hibino $^{52}$ looked at the effect of $\mathrm{NaS}$ on the upper GI tract of rats. Sixty-eight male rats were fed a diet supplemented with 5\% $\mathrm{NaS}$ and 31 control rats were fed a normal diet without $\mathrm{NaS}$. After 80 weeks, the stomachs were examined in 20 experimental and 11 controls. All 20 in the experimental group had hyperkeratosis and 5 had papillomas of the forestomach. In the experimental group, ulcers were found in the glandular stomach in 4 rats and atypical glands were seen in 4 rats. All 11 controls had normal stomachs. It is unclear what the significance of these findings is in humans.

One study done by Sasaki ${ }^{53}$ aimed to assess potential genotoxicity as a result of AS use. They fed rats NaS, sucralose, aspartame, or acesulfame, sacrificed them after 3 or 24 hours, and then ran a comet assay to test for genotoxicity. They found statistically significant DNA damage above controls for both sucralose and $\mathrm{NaS}$ in the stomach and colon. The lowest dose that induced DNA damage for $\mathrm{NaS}$ was $1000 \mathrm{mg} / \mathrm{kg}$ and was $2000 \mathrm{mg} / \mathrm{kg}$ for sucralose, which is much higher than the ADIs for these AS in humans. Acesulfame and aspartame did not increase DNA damage.

Abou-Donia ${ }^{46}$ found histopathologic changes in the colons of mice fed sucralose plus maltodextran versus control mice, which included lymphocytic infiltrates into the epithelium, epithelial scarring, and mild depletion of goblet cells.

The only study that assessed GI symptoms was performed by Kille et al. ${ }^{54}$ They found that rabbits fed sucralose developed GI symptoms (perianal soiling, scouring, and cecal enlargement) at doses of 750 and $1000 \mathrm{mg} / \mathrm{kg} /$ day. In lower doses the rabbits experienced little GI distress. However, rabbit elimination of sucralose is prolonged compared to other species and they absorb sucralose to a greater degree than other species, so the significance of these findings in humans is unclear. 


\section{Conclusions}

Although AS are widely utilized in commercially available products, there is a remarkable paucity of medical literature addressing their effects on GI physiology and symptoms. The 2 main areas on which there is data to suggest that AS affect the GI tract include motility and the gut microbiome. Most of the currently available data is derived from in vivo studies. Incretin secretion, which may indirectly result in changes in GI motility, was only shown to be increased in one human study where sucralose was combined with glucose (in other studies looking solely at the AS itself, no effect on incretin secretion was found). Additionally, the downstream effect on motility from the increased incretin secretion was not studied, so the clinical relevance of this finding is unknown. Multiple studies in animals suggest that AS exert measurable effects upon the gut microbiome. To date, only one published study has reported data from humans. The specific effects on the microbiome have been conflicting and the available studies have been heterogeneous in terms of the population studied and both the AS and doses evaluated. There is virtually no data in many other areas relevant to IBS including alterations in permeability, immune activation, and visceral sensation. There are also no studies on the effects of AS on GI symptoms in the general population, or more specifically in IBS patients.

Further research is needed to assess whether AS could be a potential cause of GI symptoms. This is especially pertinent in IBS patients, a population in whom dietary interventions are routinely utilized as a management strategy. IBS patients have been shown to have similar rates of lactose/fructose malabsorption as healthy controls, ${ }^{55}$ though they are more likely to experience symptoms from malabsorption more commonly than controls, which may be due in part to underlying abnormalities in motility and visceral hypersensitivity. ${ }^{55-57}$ Research to characterize whether AS impact upon pathophysiologic factors relevant to IBS and symptoms in affected patients would be of considerable interest and are strongly encouraged.

\section{Financial support: None.}

\section{Conflicts of interest: None.}

Author contributions: All authors contributed to the review either through review of articles and abstracts and/or preparation of the manuscript.

\section{References}

1. Lovell RM, Ford AC. Global prevalence of and risk factors for irritable bowel syndrome: a meta-analysis. Clin Gastroenterol Hepatol 2012;10:712-721, e4.

2. Longstreth GF, Thompson WG, Chey WD, Houghton LA, Mearin F, Spiller RC. Functional bowel disorders. Gastroenterology 2006;130:1480-1491.

3. Morcos A, Dinan T, Quigley EM. Irritable bowel syndrome: role of food in pathogenesis and management. J Dig Dis 2009;10:237-246.

4. Hayes P, Corish C, O'Mahony E, Quigley EM. A dietary survey of patients with irritable bowel syndrome. J Hum Nutr Diet 2014;27(suppl 2):36-47.

5. Chey WD. The role of food in the functional gastrointestinal disorders: introduction to a manuscript series. Am J Gastroenterol 2013;108:694697.

6. Ragnarsson G, Bodemar G. Pain is temporally related to eating but not to defaecation in the irritable bowel syndrome (IBS). Patients' description of diarrhea, constipation and symptom variation during a prospective 6-week study. Eur J Gastroenterol Hepatol 1998;10:415-421.

7. Ong DK, Mitchell SB, Barrett JS, et al. Manipulation of dietary short chain carbohydrates alters the pattern of gas production and genesis of symptoms in irritable bowel syndrome. J Gastroenterol Hepatol 2010;25: 1366-1373.

8. Halmos EP, Power VA, Shepherd SJ, Gibson PR, Muir JG. A diet low in FODMAPs reduces symptoms of irritable bowel syndrome. Gastroenterology 2014;146:67-75, e5.

9. Mattes RD, Popkin BM. Nonnutritive sweetener consumption in humans: effects on appetite and food intake and their putative mechanisms. Am J Clin Nutr 2009;89:1-14.

10. Sylvetsky A, Rother KI, Brown R. Artificial sweetener use among children: epidemiology, recommendations, metabolic outcomes, and future directions. Pediatr Clin North Am 2011;58:1467-1480, xi.

11. Bianchi RG, Muir ET, Cook DL, Nutting EF. The biological properties of aspartame. II. Actions involving the gastrointestinal system. J Environ Pathol Toxicol 1980;3:355-362.

12. Golightly LK, Smolinske SS, Bennett ML, Sutherland EW 3rd, Rumack BH. Pharmaceutical excipients. Adverse effects associated with 'inactive' ingredients in drug products (Part II). Med Toxicol Adverse Drug Exp 1988;3:209-240.

13. Filer LJ Jr, Stegink LD. Aspartame metabolism in normal adults, phenylketonuric heterozygotes, and diabetic subjects. Diabetes care 1989;12:67-74.

14. Stegink LD, Brummel MC, McMartin K, et al. Blood methanol concentrations in normal adult subjects administered abuse doses of aspartame. J Toxicol Environ Health 1981;7:281-290.

15. Butchko HH, Stargel WW, Comer CP, et al. Aspartame: review of safety. Regul Toxicol Pharmacol 2002;35(Pt 2):S1-S93.

16. Grotz VL, Munro IC. An overview of the safety of sucralose. Regul Toxicol Pharmacol 2009;55:1-5.

17. Schiffman SS, Rother KI. Sucralose, a synthetic organochlorine sweet- 
ener: overview of biological issues. J Toxicol Environ Health B Crit Rev 2013;16:399-451.

18. Grice HC, Goldsmith LA. Sucralose--an overview of the toxicity data. Food Chem Toxicol 2000;38(suppl 2):S1-S6.

19. Roberts A, Renwick AG, Sims J, Snodin DJ. Sucralose metabolism and pharmacokinetics in man. Food Chem Toxicol 2000;38(suppl 2):S31-S41.

20. Renwick AG. The metabolism of intense sweeteners. Xenobiotica1986;16:1057-1071.

21. Hellstrom PM, Naslund E, Edholm T, et al. GLP-1 suppresses gastrointestinal motility and inhibits the migrating motor complex in healthy subjects and patients with irritable bowel syndrome. Neurogastroenterol Motil 2008;20:649-659.

22. Grider JR. Role of cholecystokinin in the regulation of gastrointestinal motility. J Nutr 1994;124(suppl):1334S-1339S.

23. Thomas PA, Akwari OE, Kelly KA. Hormonal control of gastrointestinal motility. World J Surg 1979;3:545-552.

24. Ogawa E, Hosokawa M, Harada N, et al. The effect of gastric inhibitory polypeptide on intestinal glucose absorption and intestinal motility in mice. Biochem Biophys Res Commun 2011;404:115-120.

25. Edholm T, Degerblad M, Grybäck P, et al. Differential incretin effects of GIP and GLP-1 on gastric emptying, appetite, and insulin-glucose homeostasis. Neurogastroenterol Motil 2010;22:1191-1200, e315.

26. Savage AP, Adrian TE, Carolan G, Chatterjee VK, Bloom SR. Effects of peptide YY (PYY) on mouth to caecum intestinal transit time and on the rate of gastric emptying in healthy volunteers. Gut 1987;28:166-170.

27. Wiley JW, Lu YX, Chung OY. Mechanism of action of peptide YY to inhibit gastric motility. Gastroenterology 1991;100:865-872.

28. Sikander A, Rana SV, Prasad KK. Role of serotonin in gastrointestinal motility and irritable bowel syndrome. Clin Chim Acta 2009;403:47-55.

29. Jang HJ, Kokrashvili Z, Theodorakis MJ, et al. Gut-expressed gustducin and taste receptors regulate secretion of glucagon-like peptide-1. Proc Natl Acad Sci USA 2007;104:15069-15074.

30. Kidd M, Modlin IM, Gustafsson BI, Drozdov I, Hauso O, Pfragner R. Luminal regulation of normal and neoplastic human EC cell serotonin release is mediated by bile salts, amines, tastants, and olfactants. Am J Physiol Gastrointest Liver Physiol 2008;295:G260-G272.

31. Mace OJ, Schindler M, Patel S. The regulation of K- and L-cell activity by GLUT2 and the calcium-sensing receptor CasR in rat small intestine. J Physiol 2012;590:2917-2936.

32. Margolskee RF, Dyer J, Kokrashvili Z, et al. T1R3 and gustducin in gut sense sugars to regulate expression of $\mathrm{Na}^{+}$-glucose cotransporter 1 . Proc Natl Acad Sci USA 2007;104:15075-15080.

33. Geraedts MC, Troost FJ, Saris WH. Different tastants and low-caloric sweeteners induce differential effects on the release of satiety hormones. Food Chem 2011;129:731-738.

34. Geraedts MCP, Troost FJ, Saris WHM. Addition of sucralose enhances the release of satiety hormones in combination with pea protein. Mol Nutr Food Res 2012;56:417-424.

35. Fujita Y, Wideman RD, Speck M, et al. Incretin release from gut is acutely enhanced by sugar but not by sweeteners in vivo. Am J Physiol Endocrinol Metab 2009;296:E473-E479.

36. Ma J, Bellon M, Wishart JM, et al. Effect of the artificial sweetener, su- cralose, on gastric emptying and incretin hormone release in healthy subjects. Am J Physiol Gastrointest Liver Physiol 2009;296:G735-G739.

37. Ford HE, Peters V, Martin NM, et al. Effects of oral ingestion of sucralose on gut hormone response and appetite in healthy normal-weight subjects. Eur J Clin Nutr 2011;65:508-513.

38. Steinert RE, Frey F, Töpfer A, Drewe J, Beglinger C. Effects of carbohydrate sugars and artificial sweeteners on appetite and the secretion of gastrointestinal satiety peptides. Br J Nutr 2011;105:1320-1328.

39. Brown RJ, Walter M, Rother KI. Ingestion of diet soda before a glucose load augments glucagon-like peptide-1 secretion. Diabetes care 2009;32:2184-2186.

40. Anderson RL, Kirkland JJ. The effect of sodium saccharin in the diet on caecal microflora. Food Cosmet Toxicol 1980;18:353-355.

41. Anderson RL. Some changes in gastro-intestinal metabolism and in the urine and bladders of rats in response to sodium saccharin ingestion. Food Chem Toxicol1985;23:457-463.

42. Mallett AK, Rowland IR, Bearne CA. Modification of rat caecal microbial biotransformation activities by dietary saccharin. Toxicology 1985;36:253-262.

43. Naim M, Zechman JM, Brand JG, Kare MR, Sandovsky V. Effects of sodium saccharin on the activity of trypsin, chymotrypsin, and amylase and upon bacteria in small intestinal contents of rats. Proc Soc Exp Biol Med 1985;178:392-401.

44. Lawrie CA, Renwick AG, Sims J. The urinary excretion of bacterial amino-acid metabolites by rats fed saccharin in the diet. Food Chem Toxicol 1985;23:445-450.

45. Pfeffer M, Ziesenitz SC, Siebert G. Acesulfame K, cyclamate and saccharin inhibit the anaerobic fermentation of glucose by intestinal bacteria. Z Ernahrungswiss 1985;24:231-235.

46. Abou-Donia MB, El-Masry EM, Abdel-Rahman AA, McLendon RE, Schiffman SS. Splenda alters gut microflora and increases intestinal p-glycoprotein and cytochrome p-450 in male rats. J Toxicol Environ Health A 2008;71:1415-1429.

47. Suez J, Korem T, Zeevi D, et al. Artificial sweeteners induce glucose intolerance by altering the gut microbiota. Nature 2014;514:181-186.

48. Kidd M, Hauso Ø, Drozdov I, Gustafsson BI, Modlin IM. Delineation of the chemomechanosensory regulation of gastrin secretion using pure rodent G cells. Gastroenterology 2009;137:231-241, e1-e10.

49. Kimmich GA, Randles J, Anderson RL. Inhibition of the serosal sugar carrier in isolated intestinal epithelial cells by saccharin. Food Chem Toxicol 1988;26:927-934.

50. Kimmich GA, Randles J, Anderson RL. Effect of saccharin on the ATPinduced increase in $\mathrm{Na}^{+}$permeability in isolated chicken intestinal epithelial cells. Food Chem Toxicol 1989;27:143-149.

51. Anderson RL. Effect of saccharin ingestion on stool composition in relation to caecal enlargement and increased stool hydration. Food Chem Toxicol 1983;21:255-257.

52. Hibino T, Hirasawa Y, Arai M. Morphologic changes in the urinary bladder and stomach after long-term administration of sodium saccharin in F344 rats. Cancer Lett 1985;29:255-263.

53. Sasaki YF, Kawaguchi S, Kamaya A, et al. The comet assay with 8 mouse organs: results with 39 currently used food additives. Mutat Res 
2002;519:103-119.

54. Kille JW, Tesh JM, McAnulty PA, et al. Sucralose: assessment of teratogenic potential in the rat and the rabbit. Food Chem Toxicol 2000; 38(suppl 2):S43-S52.

55. American College of Gastroenterology Task Force on Irritable Bowel Syndrome, Brandt LJ, Chey WD, et al. An evidence-based position statement on the management of irritable bowel syndrome. Am J Gastroenterol 2009;104(suppl 1):S1-S35.
56. Zhu Y, Zheng X, Cong Y, et al. Bloating and distention in irritable bowel syndrome: the role of gas production and visceral sensation after lactose ingestion in a population with lactase deficiency. Am J Gastroenterol 2013;108:1516-1525.

57. Tomba C, Baldassarri A, Coletta M, Cesana BM, Basilisco G. Is the subjective perception of lactose intolerance influenced by the psychological profile? Aliment Pharmacol Ther2012;36:660-669. 